\title{
O Caso do Cidadão Brasileiro que Recorreu ao STF para ter Reconhecido o Direito de Candidatar-se a Cargo Político sem estar Filiado a Partido
}

\author{
SANTOS, Fabiana Prado ${ }^{[1]}$, SEPULVEDA, Luciano ${ }_{[2]}^{[2}$ DENDASCK, Carla Viana ${ }^{[3]}$
}

SANTOS, Fabiana Prado. Et.al. O Caso do Cidadão Brasileiro que Recorreu ao STF para ter Reconhecido o Direito de Candidatar-se a Cargo Político sem estar Filiado a Partido. Revista Científica Multidisciplinar Núcleo do Conhecimento. Ano 03, Ed. 07, Vol. 03, pp. 79-87, Julho de 2018. ISSN:2448-0959, Link de acesso: https://www.nucleodoconhecimento.com.br/lei/cidadao-brasileiro, DOI: 10.32749/nucleodoconhecimento.com.br/lei/cidadao-brasileiro

\section{RESUMO}

O presente trabalho discute a possibilidade do reconhecimento, pelo STF, do direito à candidatura avulsa, haja vista o questionamento do brasileiro Rodrigo Rocha Barbosa, que não conseguiu se candidatar a prefeito, na cidade do Rio de Janeiro nas eleições de 2016, por não estar filiado a partido político à época. O objetivo deste estudo é avaliar se há ou não fundamentos que levem a uma resposta, positiva, à indagação: Pode ou não, um cidadão ser elegível mesmo não estando filiado a partido político? O estudo possui cunho interpretativo-informativo, com ampla abordagem bibliográfica, nos âmbitos da jurisprudência e legislação pátria, dos tratados internacionais e múltiplas reportagens disponíveis na internet. No que se refere ao direito postulado, considerando a teoria da norma mais benéfica ao indivíduo, titular do direito, tratando a temática de direito político previsto no Pacto São José da Costa Rica, do qual o Brasil é consignatário, entendemos não poder ser outro o entendimento do STF, a não ser o reconhecimento do direito. A relevância desse estudo reflete-se no direito de votar e ser votado, no pleno exercício da cidadania, apresentando grande importância para proteção dos direitos humanos.

Palavras-chave: Política, Candidatura Avulsa, Direitos Humanos.

\section{INTRODUÇÃO}

Rodrigo Rocha Barbosa é o nome do brasileiro que ingressou em juízo questionando o fato de não ter conseguido se candidatar a prefeito do Rio de Janeiro nas eleições de 2016. Esse caso tornou-se objeto de discussão na turma de Direito Eleitoral VI (2014.2) da Universidade Estadual do Sudoeste da Bahia, a 
partir do momento em que o professor de eleitoral abordou a questão da possibilidade, ou não de, numa perspectiva futura, haver no Brasil candidaturas avulsas. Nesse sentido: Pode ou não, um cidadão ser elegível mesmo não estando filiado a partido político? Eis o objetivo do presente artigo: delinear uma possível resposta.

Para tanto, a fim de abordarmos a temática da melhor forma possível, recorremos a pesquisa bibliográfica, jurisprudências, legislação pátria, bem como reportagens sobre o tema por meio dos resultados encontrados no sistema de busca "Google" a partir do uso dos seguintes termos: "candidatura avulsa", "direitos humanos" e "reforma política".

\section{REFERENCIAL TEÓRICO}

A estrutura formal do sistema político republicano brasileiro, mesmo após a redemocratização do Brasil na década de 80, foi mantida, porém, tal manutenção não foi capaz de pacificar o debate sobre o assunto. Desde então o país já passou por várias reformas políticas, dentre elas o processo de judicialização da política, ou seja, "uso de instrumentos jurídicos que deslocaram as decisões sobre o tema para as mãos do sistema de justiça" (SILVA, 2017).

Recentemente chegou ao STF (Supremo Tribunal Federal) a discussão da possibilidade ou não de haver candidatura avulsa, a qual constitui-se na possibilidade do cidadão se candidatar a cargos políticos de pleitos majoritários mesmo não estando filiado a nenhum partido. O caso foi parar no STF após Rodrigo Rocha Barbosa ingressar com o Recurso Extraordinário com Agravo (ARE) 1054490, contra decisão que indeferiu sua candidatura avulsa a prefeito do Rio de Janeiro (RJ) nas eleições de 2016. O recurso que inicialmente teria por relator o Ministro Luiz Fux, acabou nas mão do ministro Luís Roberto Barroso, quem se tornou relator do caso, após a Presidente do Supremo determinar a redistribuição do feito, excluindo da possibilidade de relatores os Ministros Gilmar Mendes, Luiz Fux e a Ministra Rosa Weber, em virtude dos mesmos já terem participado dos julgamentos dos Embargos de Declaração e Agravo Regimental interpostos em esfera Eleitoral.

Barroso, na condição de relator, propôs a questão de ordem a ser discutida pelo Supremo Tribunal Federal. Por decisão unânime, 6 a 4, os ministros do STF admitiram a discussão da matéria na Corte, tendo considerado inclusive, a grande repercussão que terá uma decisão favorável à candidatura avulsa para as eleições majoritárias.

Muito embora, pelo adiantado do tempo, não seja mais possível a aplicação de uma decisão favorável já para as eleições de 2018, - uma vez que estamos em novembro de 2017 e tal decisão, para ter validade para o próximo pleito, teria que se dar até 01 de outubro de 2017 e, até então, o STF não julgou o mérito, aparentemente de modo proposital, pois conforme enfatizou o TSE (Tribunal Superior Eleitoral), em nota lançada 03 de outubro de 2017, caso fosse favorável tal decisão, poderia ocorrer o comprometimento da segurança nacional no tocante às eleições de 2018, já que cerca de $80 \%$ dos softwares a serem utilizados no referido pleito já estão prontos e em fase de testes -, cumpri-nos discutir alguns dos principais aspectos que permeiam a questão em busca de uma plausível resposta.

Sobre as condições de elegibilidade, a Constituição da República de 1988 é taxativa ao determinar em seu art. $14, \S 3^{\circ}$, inciso $\mathrm{V}$, a necessidade de filiação partidária. A lei 4.737/65 (Código Eleitoral) em seu artigo $3^{\circ}$ estabelece que: "Qualquer cidadão pode pretender investidura em cargo eletivo, respeitadas as 
condições constitucionais e legais de elegibilidade e incompatibilidade". Nesse sentido, depreende-se desses textos normativos que a filiação é condição sine qua non para que o indivíduo possa ser eleito.

O próprio TSE, ao tradar da filiação partidária, reporta que esta é o ato no qual um eleitor adota, aceita e passa a integrar um partido, cujo vínculo estabelecido entre cidadão e partido constitui condição de elegibilidade, concluindo que "para concorrer a cargo eletivo, o eleitor deve estar filiado ao partido a pelo menos seis meses antes da data fixada para as eleições, conforme dispõe o art. $9^{\circ}$ da Lei n 9.504/1997”.

O ministro Dias Toffoli, ao relatar a ADI 1.817, pontua que:

A noção de elegibilidade (condição para o exercício regular do direito de candidatura) abarca o mandamento de que a satisfação dos seus requisitos, dentre os quais a filiação partidária, deve ser atestada de maneira prévia ao pleito eleitoral. [...] A relação dialógica entre partido político e candidato é indissociável, em face da construção constitucional de nosso processo eleitoral. [ADI 1.817, rel. min. Dias Toffoli, j. 28-5-2014, P, DJE de 1º-8-2014.]

O artigo $1^{\circ}$ da Lei 9.096/95 dispõe que:

O partido político, pessoa jurídica de direito privado, destina-se a assegurar, no interesse do regime democrático, a autenticidade do sistema representativo e a defender os direitos fundamentais definidos na Constituição Federal (lei 9.096/95 - Partidos Políticos).

Dirley Junior (2015), em consonância com os dispositivos de leis citados, entende os partidos políticos como um dos mais significativos instrumentos para a consolidação da democracia, sendo portanto, indispensável a filiação para exercer a capacidade de ser votado ou eleito.

Diante do exposto, observa-se que já existe um certo entendimento voltado para o reconhecimento da necessidade de filiação partidária enquanto condição de elegibilidade, o que, do ponto de vista teórico, traria maior estabilidade institucional, uma vez que torna os partidos políticos mais fortes.

Entretanto, numa análise mais profunda, podemos entender a filiação partidária como uma limitação à competitividade, uma vez que cada partido político traz consigo uma ideologia, da qual o filiado deve partilhar para integrá-lo. Caso o cidadão não se identifique com nenhumas das ideologias postas pelos múltiplos partidos, fica ele tolhido de exercer o seu direito de elegibilidade, a não ser que vá de encontro com princípios próprios, o que fere totalmente a Constituição, quando esta estabelece não só a liberdade de expressão, como também a livre associação, positiva ou negativa.

É sabido de todos que o filiado está totalmente vinculado ao partido, podendo inclusive, sofrer sérias sansões caso venha a incorrer em infidelidade partidária. O art. 25, da lei 9.096/95 é muito claro ao dizer que:

O estatuto do partido poderá estabelecer, além das medidas disciplinares básicas de caráter partidário, normas sobre penalidades, inclusive com desligamento temporário da bancada, suspensão do direito de voto nas reuniões internas ou perda de todas as prerrogativas, cargos e funções que exerça em decorrência da representação e da proporção partidária, na respectiva Casa Legislativa, ao parlamentar que se opuser, pela atitude ou pelo voto, às diretrizes legitimamente estabelecidas pelos órgãos partidários (lei 9.096/95 


\section{- Partidos Políticos).}

Por esse viés, os partidos políticos acabam por deterem o monopólio do sistema eleitoral, logo, o mandado pertence ao partido, sendo que, ao menos no tocante às eleições proporcionais, já é cediço que o titular de mandato que mudar de partido sem justa causa perderá o mandato, quanto mais aquele que se desfiliar e manter-se sem partido.

Nessa esteia, é nítido que a obrigatoriedade de filiação partidária vai totalmente de encontro com o que preceitua o artigo 23, inciso 1, alínea "b" do pacto São José da Costa Rica, o qual estabelece, no tocante aos direitos políticos, que todos os cidadãos devem gozar do direito de "votar e ser eleito em eleições periódicas, autênticas, realizadas por sufrágio universal e igualitário e por voto secreto, que garantam a livre expressão da vontade dos eleitores" (grifamos). Assim, impor ao cidadão que ele se filie e defenda uma ideologia partidária da qual não comunga, fortalece ainda mais a ideia de cerceamento de liberdade de expressão e associação, já que o impede de ser eleito caso ele não se submeta à filiação partidária, estando portando privado de direito previsto em pacto internacional do qual o Brasil é consignatário.

De fato não é uma discussão fácil, o próprio Barroso, ao tratar da questão ponderou que:

A experiência com candidaturas avulsas é associada com a República Velha, marcada por instabilidade institucional e partidos fracos. A vedação pode ser associada a mecanismos voltados à limitação da competitividade eleitoral e favorecimento da manutenção de uma elite dominante no poder. O passado condena tanto uma experiência como outra (BARROSO,2017).

Através de parecer ao STF, a atual procuradora-geral da República, Raquel Dodge, defendeu a possibilidade de candidaturas avulsas, sustentando seu posicionamento no Pacto São José da Costa. Temos em tela, sem dúvidas, um conflito de normas.

A situação seria simplesmente resolvida, caso se tratasse de um conflito entre normas nacionais. A Lei de Introdução às Normas do Direito Brasileiro é bem clara quanto à adoção do critério cronológico, ao estabelecer em seu artigo, $2^{\circ}, \S 1_{-}^{\circ}$ que: "A lei posterior revoga a anterior quando expressamente o declare, quando seja com ela incompatível ou quando regule inteiramente a matéria de que tratava a lei anterior". Outro critério também adotado é o da especialização, aqui, norma especial prevalece sobre norma geral. Entretanto, no caso em tela o conflito se verifica entre uma norma nacional e um pacto internacional do qual o Brasil é consignatário.

A relação entre o direito internacional e o direito interno constitui-se em figura difícil de se entender. Basicamente surgiram duas teorias na busca de uma explicação plausível, uma intitulada dualista e outra monista.

De acordo com Mazzuolli (2000), a corrente dualista, ao tratar da diferença entre o direito internacional e o direito interno, entende que as regras internas dão ao Estado condição soberana de poder ilimitado, impondo aos seus dependentes total subordinação, o que não ocorre quanto ao direito internacional, este impõe apenas uma obrigação moral, em que, deixando de ser descumprida, poderá gerar responsabilização no plano internacional. Nesse sentido, direito internacional e interno seriam pareados, não podendo um direito da gente revogar outro da gente de ordem interna. Segundo Araújo: 
"as normas de Direito Internacional não têm força cogente no interior de um Estado senão por meio da recepção, isto é, em decorrência de um ato do seu Poder Legislativo que as converte em regras de Direito Interno, não sendo possível, por via de consequência, colisões entre as duas ordens jurídicas" (ARAÚJO, 1997:44)

Nesse sentido, para os dualistas, se não há norma interna que recepciona o preceito internacional, este não prevalecerá sobre o direito interno. Já para os monistas, uma vez ratificado o tratado internacional, não há necessidade de um novo diploma para materialização do compromisso. O próprio ato de ratificação importa em comprometimento jurídico de assunção de compromisso.

Segundo Mazzuolli (2000), a corrente monista se divide em duas vertentes:

I - monismo internacionalista $=$, baseia-se na unicidade da ordem jurídica, onde há uma primazia do direito internacional tido como supralegal, não sendo admissível que uma norma interna vá de encontro a um preceito internacional;

II - monismo nacionalista = baseia-se na primazia do direito nacional de cada Estado soberano, quando seria facultativa a adoção dos preceitos do direito internacional. Desse modo, admitem a integração do produto convencional ao direito interno, mas não em grau hierárquico superior.

O Brasil, durante muitos anos, de acordo com o posicionamento do STF, enquadrou-se no sistema monismo nacionalista. Com verdadeiro culto à Constituição, entendia-se que nenhum outro texto poderia sobrepor-se a ela, sendo que o tratado, uma vez ratificado, possuía força de lei ordinária, podendo tanto revogar disposições em contrário ou ser revogado diante de lei posterior. Entretanto, em decisão recente, baseado no Pacto São José da Costa Rica, o STF mudou seu posicionamento ao expedir a Súmula Vinculante 25, a qual prevê a ilicitude da prisão civil de depositário infiel, mesmo esta estando prevista no art. $5^{\circ}$, inciso LXVII da Constituição da República.

Nesse sentido, no caso do depositário infiel, entendemos que, por se tratar de conflito situado no plano dos direitos humanos, prevaleceu a norma mais benéfica ao indivíduo, titular do direito. Segundo Piovesan:

O critério ou princípio da aplicação do dispositivo mais favorável às vítimas é não apenas consagrado pelos próprios tratados internacionais de proteção dos direitos humanos, mas também encontra apoio na prática ou jurisprudência dos órgãos de supervisão internacionais. Isto é, no plano de proteção dos direitos humanos interagem o Direito Internacional e o Direito interno movidos pelas mesmas necessidades de proteção, prevalecendo as normas que melhor protejam o ser humano, tendo em vista que a primazia é da pessoa humana (PIOVESAN, 1996).

Mazzuolli (2000), ao tratar dos direitos humanos, enfatiza a questão desses serem direitos inscritos (positivados), sobretudo, em tratados internacionais. Os direitos humanos, assim como os direitos fundamentais têm por base a proteção dos direitos das pessoas, do modo mais amplo possível. Nesse sentido, a utilização do princípio da primazia da norma mais favorável à pessoa humana, no direito brasileiro, tem o condão de dar máxima proteção aos indivíduos, seja por meio da tutela jurisdicional ou em virtude de leis, tratados e demais normas jurídicas. 
Em pesquisa recente encomendada pelo Tribunal Superior Eleitoral (TSE) à empresa Checon Pesquisa/Borghi, constatou-se que: "mais de um em cada dois entrevistados se posicionou de forma favorável à candidatura avulsa, e menos de $20 \%$ declararam não saber ou preferiram não responder" (TSE 2017).

Nesse sentido, é nítido o posicionamento da população a favor da livre candidatura, ou seja, do fim da limitação da competitividade eleitoral.

\section{CONSIDERAÇÕES FINAIS}

Ante todo o exposto, considerando que o caso em tela trata de questão que versa sobre direito humano reconhecido e positivado, considerando ainda o caráter supralegal dos pactos internacionais, entendemos que não deverá ser outro o posicionamento do STF, senão a admissão da candidatura em detrimento da filiação partidária, uma vez que consiste em posicionamento mais benéfico ao titular do direito, previsto em legislação avançada sobre dos direitos humanos, Pacto São José da Costa Rica. Após o exposto neste estudo, entende-se que a legislação permite que um cidadão possa ser elegível mesmo sem estar filiado a um partido político.

\section{REFERÊNCIAS}

ARAÚJO, Luis Ivani de Amorim. Curso de direito internacional público. 9. ed. Rio de janeiro : Forense, 1997. p. 44.

BARBIÉRI, Luis Felipe. STF não julga mérito e candidaturas sem partido não valem para 2018. Disponível em: https://www.poder360.com.br/justica/stf-nao-julga-merito-e-candidaturas-sem-partidonao-valem-para-2018/. Acesso em: 30 set. 2017.

BRASIL. Supremo Tribunal Federal. Recurso Extraordinário com Agravo 1.054.490. Rio de Janeiro. Disponível em: www.stf.jus.br/portal/processo/ verProcessoPeca.asp?id=312382124\&tipoApp. Acesso em 15 set. 2017.

BRASIL. Supremo Tribunal Federal. Súmula Vinculante $\mathbf{n}^{\mathbf{0}} \mathbf{2 5}$. Disponível em: http://www.stf.jus.br/portal/jurisprudencia/menuSumario.asp?sumula=1268. Acesso em: 06 out. 2017.

BRASIL. Constituição Da República Federativa do Brasil de 1988. Disponível em:http://www.planalto.gov.br/ccivil_03/constituicao/constituicao.htm. Acesso em: 06 out. 2017.

BRASIL. Lei $\mathrm{n}^{\circ}$ 4.737, de 15 de Julho de 1965 (Código Eleitoral). Disponível em: http://www.planalto.gov.br/ccivil_03/leis/L4737.htm. Acesso em: 06 out. 2017.

BRASIL. Lei $\mathbf{n}^{0} \mathbf{9 . 0 9 6}$, de 19 de Setembro de 1995. Disponível em: http://www.planalto.gov.br/ccivil_03/leis/L9096.htm. Acesso em: 06 out. 2017.

BRASIL. Tribunal Superior Eleitoral. Notícias. Cândidaturas Avulsas. Disponível em: http://www.tse.j us.br/imprensa/noticias-tse/2015/Fevereiro/pesquisa-revela-o-que-pensam-eleitores-sobre-temaseleitorais. Acesso em: 25 de set. 2017. 
BRASILIENSE, Correio. TSE: Candidatura avulsa "compromete totalmente a segurança da eleição". Disponível em: http://www.correiobraziliense.com.br/ app/noticia/politica/2017/10/03/internas_ polbraeco,631104/tse-candidatura-avulsa__compromete-totalmente-a-seguranca-da-eleicao .shtml_Acesso em: 25 de set. 2017.

JUNIOR, Dirley da Cunha. Curso de Direito Constitucional. 10ª edição. Salvador:Jus Podivm. 2015.

MAZZUOLI, Valerio de Oliveira . A incorporação dos tratados internacionais de proteção dos direitos humanos no ordenamento brasileiro. Disponível em: http://www2.senado.leg.br/bdsf/bitstream/handle/id/618/r147-15.PDF. Acesso em 06 out. 2017.

PIOVESAN, Flávia. A Constituição De 1988 E Os Tratados Internacionais De Proteção Dos Direitos Humanos. Disponível em: http://www.pge.sp.gov.br/ centrodeestudos/ revistaspge/revista3/rev6.htm. Acesso em 20 set. 2017.

SILVA, Cristian. Reforma Política no Brasil. Disponível em: http://www.Jose pimentel.com.br/sites/default/files/documentos/reforma_politica_no_brasil.pdf.Acesso em 01 out. 2017.

TRATADO InTERnACIONAL. Convenção Americana de Direitos Humanos (1969) - Pacto de San José da Costa Rica. Disponível em: http://www.pge.sp.gov.br/ centrodeestudos/bibliotecavirtual/instrumentos/sanjose.htm. Acesso em: 30 set. 2017.

[1] Graduada em História, possui Especialização em Educação, Cultura e Memória pela Universidade Estadual do Sudoeste da Bahia - UESB. Atualmente é acadêmica do Curso de Direito 2014.2 VI, da Universidade Estadual da Bahia - UESB.

${ }^{[2]}$ Professor de Direito Eleitoral na Universidade Estadual da Bahia - UESB

Teóloga, Doutora em Psicanálise Clínica. Atua há 15 anos com Metodologia Científica (Método de Pesquisa) na Orientação de Produção Científica de Mestrandos e Doutorandos. Especialista em Pesquisas de Mercado e Pesquisas voltadas a área da Saúde.

\section{PUBLIQUE SEU ARTIGO CIENTÍFICO EM:}

https://www.nucleodoconhecimento.com.br/enviar-artigo-cientifico-para-submissao 